\title{
sciendo
}

\section{EFFECT OF FERMENTED RAPESEED MEAL AS A FEED COMPONENT ON THE REDOX AND IMMUNE SYSTEM OF PREGNANT SOWS AND THEIR OFFSPRING*}

\author{
Anna Czech, Anna Stępniowska*, Martyna Kiesz \\ Department of Biochemistry and Toxicology, Faculty of Animal Sciences and Bioeconomy, \\ University of Life Sciences in Lublin, Akademicka 13, 20-950 Lublin, Poland \\ •Corresponding author: anna.stepniowska@up.lublin.pl
}

\begin{abstract}
The aim of the study was to assess the effect of dried fermented rapeseed meal (FRSM) in diets for sows on blood redox and immunological parameters, taking into account the physiological period (pregnancy or lactation) and age (primiparous vs multiparous sows). The experiment also aimed to determine how FRSM administered to pregnant sows, affects the antioxidant and immune systems of piglets. The animals were divided into 4 groups of 15 animals each. Control groups of primiparous $\left(C_{G}\right)$ and multiparous sows $\left(C_{S}\right)$ received a standard diet for pregnant or lactating sows. Experimental groups of primiparous $\left(E_{G}\right)$ and multiparous sows $\left(E_{s}\right)$ received feed with a $4 \%$ share of FRSM in place of soybean meal up to day 100 of gestation, $9 \%$ share of FRSM from day 100 of gestation to day 7 of lactation, and then again 4\% share of FRSM until the end of lactation. In the blood plasma of pregnant sows fed diet with FRSM addition, higher FRAP value and vitamin C, uric acid (UA), immunoglobulin IgG content, lymphocytes (LYM) count and a lower content of malondialdehyde (MDA), lipid hydroperoxides (LOOH), immunoglobulin IgM was noted than in the blood plasma of control sows. Both primiparous and multiparous lactation sows whose feed included FRSM had higher catalase (CAT) activity, higher FRAP, vitamin C, immunoglobulin IgG and IL-6 content, and lower UA content than the control sows. Piglets born to sows fed diet with FRSM addition had significantly higher FRAP values, vitamin C, IgG, and IL-6 content and white blood cells (WBC) count and lower MDA and UA content in the blood plasma than piglets born to sows from control group. Multiparous sows compared to primiparous sows had higher CAT activity, and higher vitamin C, LOOH, creatinine (CREAT), and IgM content. Elevated FRAP, and CREAT levels and reduced MDA content were also observed in the plasma of the multiparous sows compared to primiparous sows during lactation. Multiparous lactation sows compared to primiparous sows had lower WBC count, and IgG and IgM content. Piglets born to multiparous sows had higher FRAP values, LOOH content and IgA content while lower MDA content compared to piglets born to primiparous sows. The inclusion of dried fermented rapeseed meal in feed for sows significantly stimulates antioxidant processes in primiparous and multiparous sows and in their piglets. The inclusion of dried fermented rapeseed meal in the diet of sows stimulates antioxidant processes in primiparous and multiparous sows and in their piglets. This is responsible for
\end{abstract}

*This research was supported by the Ministry of Science and Higher Education: University of Life and Sciences in Lublin (no. ZKT/S/20/2021-ZiR). 
stimulation of the immune system (increased LYM counts and IgG titres in the blood plasma). The improved antioxidant status in the plasma suggests that dried fermented rapeseed meal stimulated the immune system of pregnant and lactating sows and their newborn offspring.

Key words: fermented rapeseed meal, sows, piglets, antioxidant, immune system

Rapeseed meal use in feeding of sows and piglets is limited by the presence of numerous antinutritional factors (ANF), such as glucosinolates, tannins, phytic acid or non-starch polysaccharides (Jakobsen et al., 2015; Czech and Grela, 2004). The presence of anti-nutritional compounds is particularly dangerous for primiparous sows, in which pregnancy, farrowing and weaning are associated with dynamic adaptive changes (anatomical, physiological and metabolic). One of the methods for reducing the amount of ANFs in rapeseed meal is to subject it to the action of microorganisms (fermentation) whose enzymes can effectively hydrolyse proteins and, above all, break down antinutrients (Canibe and Jensen, 2012; Jha and Leterme, 2012). Use of fermented rapeseed meal (FRSM) in the sow's diet may result in increased intestinal immunity (Gao et al., 2009), in better use of mineral compounds and improvement of blood parameters of sows and piglets (Czech et al., 2020; Tomaszewska et al., 2019). Stimulation of the sow's immune system is also associated with an increase in the level of immunoglobulins in the blood and in the colostrum. Maternal immunoglobulins (IgG, IgM, IgA) derived from colostrum, due to the total permeability of the intestines, penetrate through enterocytes into the bloodstream of piglets, which has a positive effect on the health, survival and general condition of piglets (Declerck et al., 2015).

Activation of the immune system to secrete immunoglobulins through the gastrointestinal mucosa is associated with the presence of probiotic microorganisms found in fermented feed (Missotten et al., 2015). The presence of microorganisms stimulates the production of organic acids, which by lowering the intestinal $\mathrm{pH}$ create an unfavourable growth environment for some enteropathogens, thereby improving the gut microbiota and thus animal health (Wang et al., 2012). Diet with fermented products affects not only the humoral response (immunoglobulin content, lysozyme activity, and cytokine production), but also cellular immunity. The reduction in the heterophil/lymphocyte ratio observed in chickens fed diet with addition of fermented products suggests that these products may suppress the immune response (Sugiharto and Ranjitkar, 2019).

Thus far, no studies have been conducted on the use of FRSM in the diet of sows during pregnancy and lactation; therefore, the experiment may introduce new information regarding this valuable protein feed component and its effect on the antioxidant and immune system. In choosing the amount of FRSM in diet for sows, we kept in mind that in addition to the benefits of fermentation, fermented raw materials also contain compounds that can reduce the palatability of feed (acetic acid and sinapine) and adversely affect metabolic reactions (biogenic amines formed during fermentation, e.g. cadaverine, putrescine and histamine), which is undesirable for pregnant and lactating sows (Canibe and Jensen, 2012). 
It has been assumed that the addition of fermented rapeseed meal to feed will improve the antioxidant and the immune status of sows. The aim of the study was to assess the effect of FRSM in diets for sows on blood redox and immunological parameters, taking into account the physiological period (pregnancy or lactation) and age (primiparous vs multiparous sows). The experiment also aimed to determine how FRSM administered to pregnant sows, affects the antioxidant and immune systems of piglets.

\section{Material and methods}

The experimental procedure was approved by the Local Ethics Commission for Experiments with Animals in Lublin (approval no. 21/2016).

\section{Experimental design}

The experimental material comprised 60 Yorkshire sows mated with Danish Landrace boars. These included 30 primiparous gilts (average body weight $150 \mathrm{~kg} \pm 8 \mathrm{~kg}$; average backfat thickness $18 \mathrm{~mm} \pm 1.5 \mathrm{~mm}$ ) and 30 multiparous sows after their second lactation (average body weight $250 \mathrm{~kg} \pm 11 \mathrm{~kg}$; average backfat thickness $24 \mathrm{~mm} \pm 2 \mathrm{~mm}$ ). They were randomly divided into two groups of equal size - control and experimental. The animals in the control groups $\mathrm{C}_{\mathrm{G}}$ (gilts) and $\mathrm{C}_{\mathrm{S}}$ (sows) received a standard diet for pregnant or lactating sows, depending on the reproductive period. Experimental groups $\mathrm{E}_{\mathrm{G}}$ and $\mathrm{E}_{\mathrm{S}}$ were gilts and multiparous sows, respectively, receiving feed with a $4 \%$ share of fermented rapeseed meal in place of soybean meal from $28 \mathrm{~d}$ to $100 \mathrm{~d}$ of gestation. In addition, from $100 \mathrm{~d}$ of gestation to $7 \mathrm{~d}$ of lactation, the sows in these groups received feed with a $9 \%$ share of FRSM, and then again, a diet with a 4\% share of FRSM until the end of lactation. During gestation, the sows stayed in pens with 5 animals apiece (group feeding), and from two weeks before parturition until weaning they were housed in individual stalls (individual feeding). FRSM was obtained from European Protein AS (Bække, Denmark).

\section{Animal diets}

The sows were fed dry diet in accordance with NRC (2012). Gestation diets (2.5 kg per day) were supplied twice a day (08:00 and 18:00). On d 108 of gestation, sows were transported to farrowing stalls and individually fed. After farrowing, all sows received the experimental lactation diet. The lactation diet was supplied three times a day $(08: 00,12: 00$ and 18:00), starting at $2.0 \mathrm{~kg}$ /day and increasing by $0.5 \mathrm{~kg}$ /day during the first week. Afterwards, sows had free access to the diet until they were weaned on d 28 of lactation. Sows were provided ad libitum access to water during the entire experimental trial. The content of nutrients and ANFs such as glucosinolates, tannins, phytate phosphorus in the diets for the animals in the control and experimental groups are given in Table 1. Details of feed intake and methods for the determination of nutrients and ANFs are included in Grela et al. (2019). 


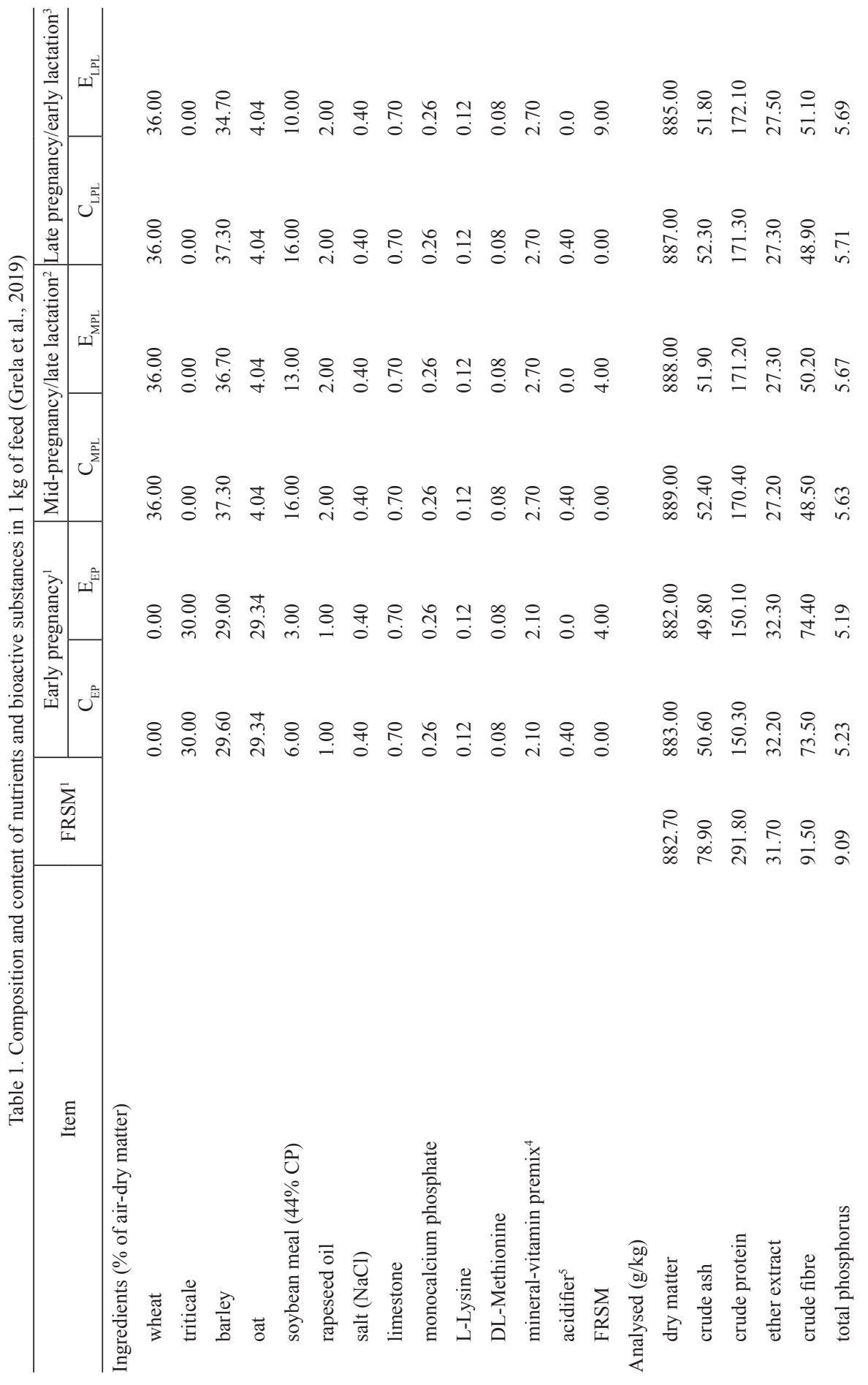




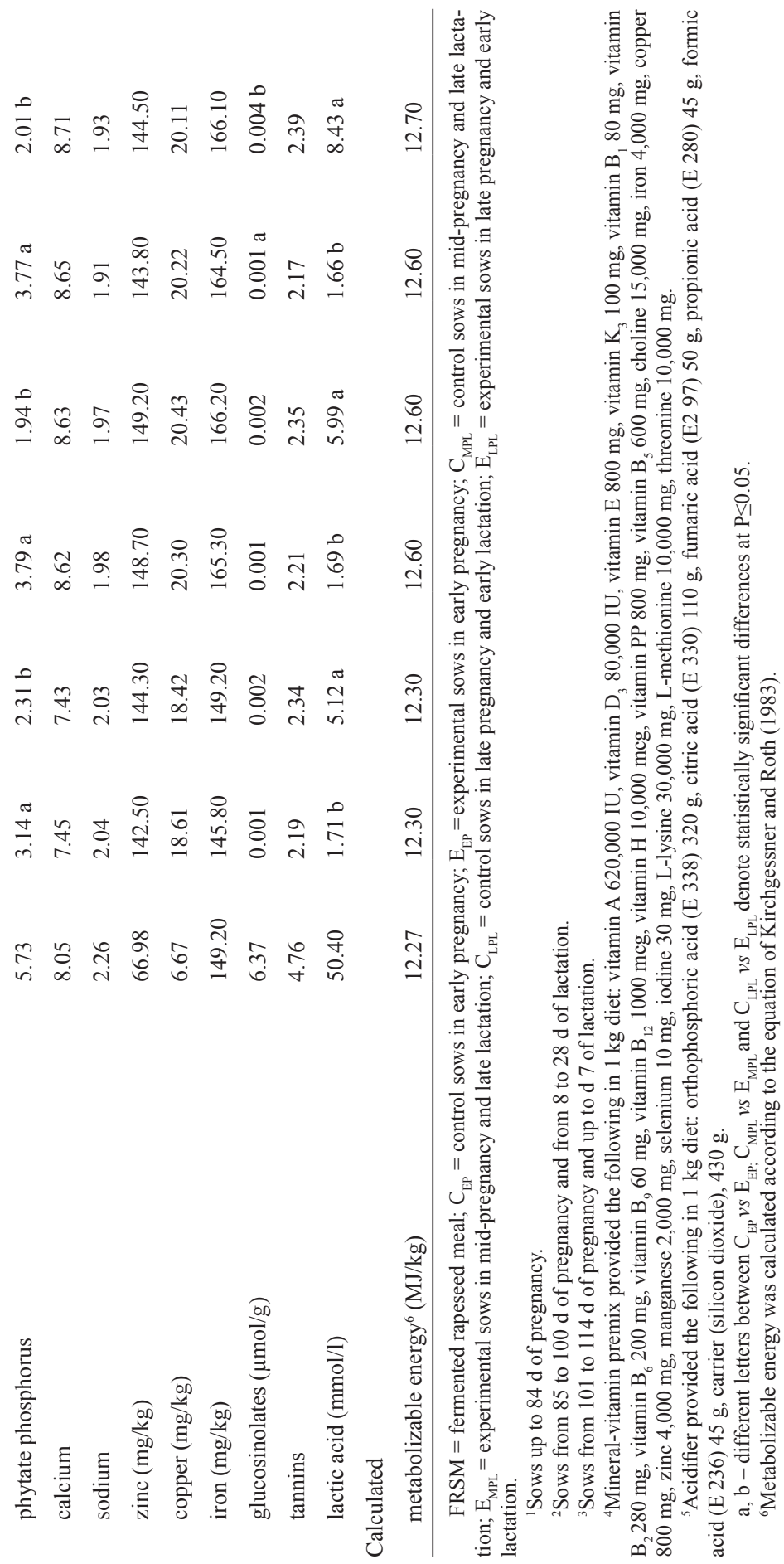


The piglets fed on the sows' milk and additionally received a prestarter diet. Prestarter feed (13.6 MJ ME, $215 \mathrm{~g} \mathrm{CP}$, total lysine $13.5 \mathrm{~g}$ ) was available to the piglets ad libitum from d 10 of age and continued for 1 week after weaning. From the second week, the piglets were fed a starter diet (13.5 MJ ME, $207 \mathrm{~g} \mathrm{CP}$, total lysine $11.5 \mathrm{~g}$ ). The diets for piglets did not contain FRSM, and their nutritional value and vitamin and mineral content were in accordance with NRC (2012) for piglets weighing 5 to $7 \mathrm{~kg}$.

\section{Experimental procedures}

Blood samples were taken from 6 sows from each group in two periods: at $100 \mathrm{~d}$ of pregnancy (late pregnancy) and at $27 \mathrm{~d}$ of lactation (late lactation). Blood was always collected from the same animals. Blood from piglets was taken at $27 \mathrm{~d}$ of age (before weaning), from 2 piglets from each sow (one gilt and one barrow), taking into account the average body weight in the litter.

\section{Blood analysis}

The haematological parameters determined in whole blood were the white blood cell count (WBC) and the percentage composition of white blood cells (leukogram), i.e. the percentage of neutrophils (NEU), lymphocytes (LYM) and the sum of monocytes, eosinophils and basophils (MID). The determinations were made in an ABACUS-Vet analyser. The blood samples were immediately aliquoted into tubes containing heparin as an anticoagulant. The blood samples were centrifuged for 15 at $380 \times g$ and $4^{\circ} \mathrm{C}$, and the resulting plasma was stored at $-20^{\circ} \mathrm{C}$ until analysis. Plasma content of uric acid (UA), urea (UREA), creatinine (CREAT), and bilirubin (BIL) was determined by spectrophotometry using Cormay monotests.

The content of immunoglobulins IgA (cat. no. EP0076), IgG (cat. no. EP0084) and IgM (cat. no. EP0085) and interleukin 6 (IL-6) (cat. no. EP0099) in the blood plasma were determined using ELISA kits (Wuhan Fine Biotech Co., Ltd., China) and ELISA plate reader (spectrophotometric method). The total antioxidant potential of the plasma (FRAP), level of malondialdehyde (MDA), lipid hydroperoxide $(\mathrm{LOOH})$, and vitamin $\mathrm{C}$, activity of superoxide dismutase (SOD) and catalase (CAT) in the blood plasma was determined according to Czech et al. (2017).

\section{Statistical analysis}

The data on diets and blood parameters of the sows and piglets were subjected to statistical evaluation by two-factor analysis with interaction, taking into account the following factors:

$$
y_{i j k}=C_{i}+F_{j}+(C \times F)_{i j}+e_{i j k}
$$

where: $y_{i j k}-$ observations; $C_{i}-$ effect of reproductive cycle (primiparous gilts or multiparous sows); $F_{j}$ - effect of feeding group (control or experimental - the effect of dried fermented rapeseed meal); $(C \times F)_{i j}$ - effect of interaction between reproductive cycle and diet; $e_{i j k}$ - error. Statistical significance between treatments was based on $\mathrm{P}<0.05$ and $\mathrm{P}<0.01$. Analyses were performed in the GLM procedure of SAS 9.4 (SAS Institute, Cary NC). Correlation coefficients between the content of IgG, IgA and IgM 
in blood plasma of pregnant sows, lactating sows and colostrum and their content in piglet's blood plasma was calculated using Pearson's correlation analysis.

\section{Results}

\section{Effect of FRSM}

In the blood plasma of pregnant sows fed diet with FRSM addition, higher FRAP value $(\mathrm{P}<0.001)$ and vitamin $\mathrm{C}$ content $(\mathrm{P}<0.001)$ and a lower content of MDA $(\mathrm{P}<0.001)$ and $\mathrm{LOOH}(\mathrm{P}=0.039)$ was noted than in the blood plasma of control sows. Primiparous and multiparous sows receiving feed with FSRM during pregnancy had higher plasma levels of UA $(\mathrm{P}=0.011)$ than the control sows (Table 2$)$. Higher IgG $(\mathrm{P}=0.042)$ and lower IgM level $(\mathrm{P}=0.037)$ was noted in the blood plasma of pregnant sows fed diet with FRSM addition compared to sows from control groups. In the blood of pregnant sows fed diet with FRSM addition, higher LYM count $(\mathrm{P}=0.001)$, with a significantly lower count of NEU and NEU/LYM ratio $(\mathrm{P}<0.001$, both) was noted than in the blood of control sows (Table 3$)$.

Both primiparous and multiparous lactation sows whose feed included FRSM had higher CAT activity $(\mathrm{P}=0.005)$, higher FRAP, and vitamin $\mathrm{C}$ content $(\mathrm{P}<0.001$; $\mathrm{P}=0.001$, respectively), and lower UA content $(\mathrm{P}=0.037)$ than the control sows (Table 4). All sows receiving a diet with FRSM during lactation had significantly higher level of IgG and IL-6 ( $<<0.001$, both) in blood plasma compared to sows from control groups (Table 5).

Piglets born to sows fed diet with FRSM addition had significantly higher FRAP values $(\mathrm{P}<0.001)$, vitamin $\mathrm{C}$ and $\mathrm{BIL}$ content $(\mathrm{P}=0.022 ; \mathrm{P}=0.004$, respectively $)$ and significantly lower MDA and UA content $(\mathrm{P}=0.007 ; \mathrm{P}=0.009$, respectively) in the blood plasma than piglets born to sows from control group (Table 6). Piglets born to primiparous and multiparous sows receiving feed with FRSM had a significantly higher WBC count $(\mathrm{P}<0.001)$, including LYM count $(\mathrm{P}=0.007)$, with a significantly lower count of NEU and NEU:LYM ratio $(\mathrm{P}=0.025 ; \mathrm{P}=0.040$, respectively). In blood plasma of piglets born to sows receiving a diet with FRSM higher IgG and Il6 level $(\mathrm{P}<0.001$, both) was noted compared to piglets born to sows from control group (Table 7).

\section{Effect of reproductive cycle}

Multiparous sows compared to primiparous sows had higher CAT activity $(\mathrm{P}<0.001)$, and higher vitamin $\mathrm{C}, \mathrm{LOOH}, \mathrm{CREAT}$, and IgM content $(\mathrm{P}<0.001 ; \mathrm{P}=$ $0.005 ; \mathrm{P}<0.001 ; \mathrm{P}<0.001$, respectively) (Table 2, 3). Elevated FRAP $(\mathrm{P}=0.011)$ and CREAT $(\mathrm{P}<0.001)$ levels and reduced MDA content $(\mathrm{P}=0.001)$ were also observed in the plasma of the multiparous sows compared to primiparous sows during lactation (Table 4). Multiparous lactation sows compared to primiparous sows had a significantly lower WBC count $(\mathrm{P}=0.006)$, and $\operatorname{IgG}$ and $\operatorname{IgM}$ content $(\mathrm{P}<0.001 ; \mathrm{P}=0.001$, respectively) (Table 5). Piglets born to multiparous sows had higher FRAP values $(\mathrm{P}=0.049), \mathrm{LOOH}$ content $(\mathrm{P}=0.046)$ and $\operatorname{IgA}(\mathrm{P}=0.009)$ content while lower MDA content $(\mathrm{P}=0.041)$ compared to piglets born to primiparous sows (Table 6,7$)$. 


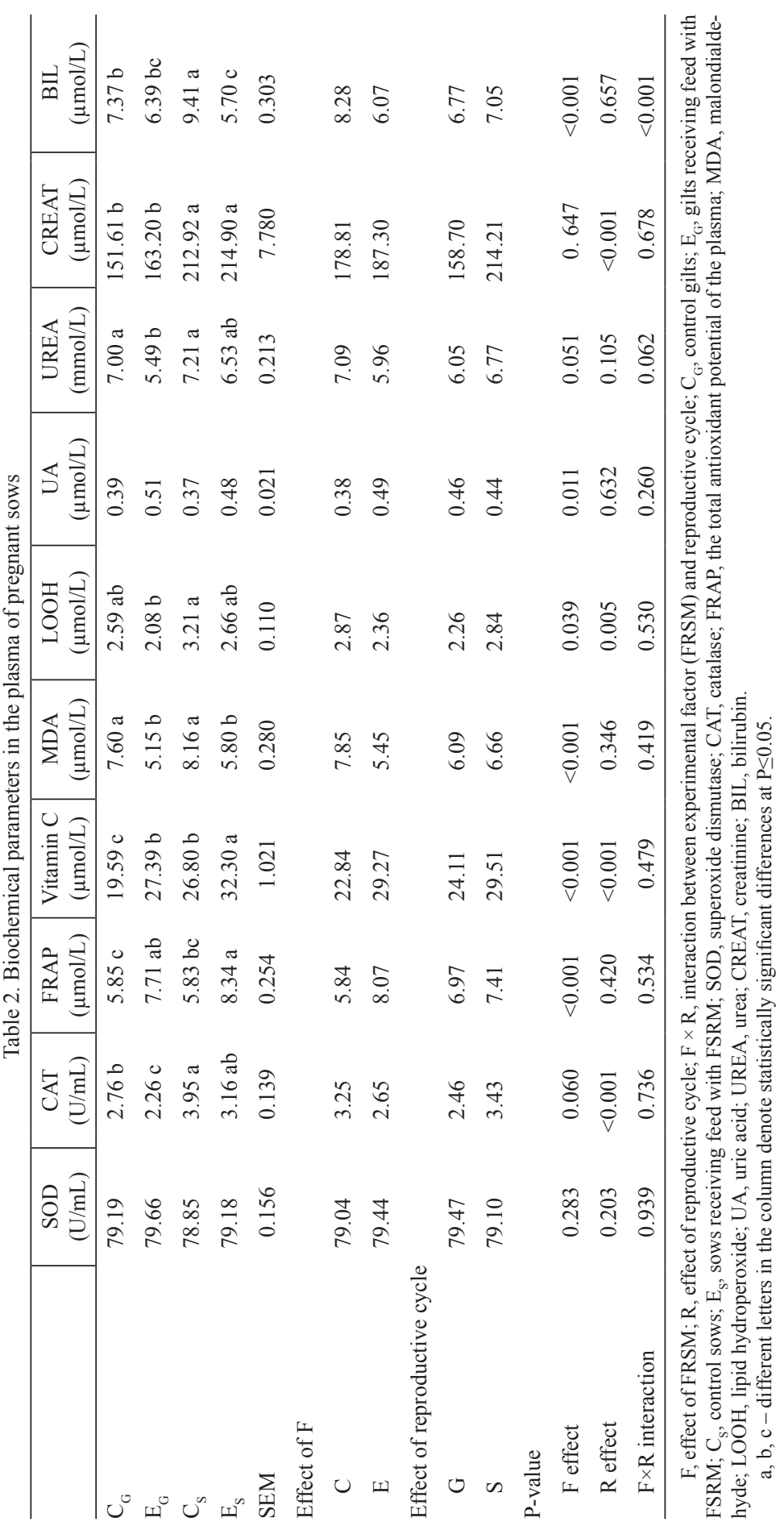




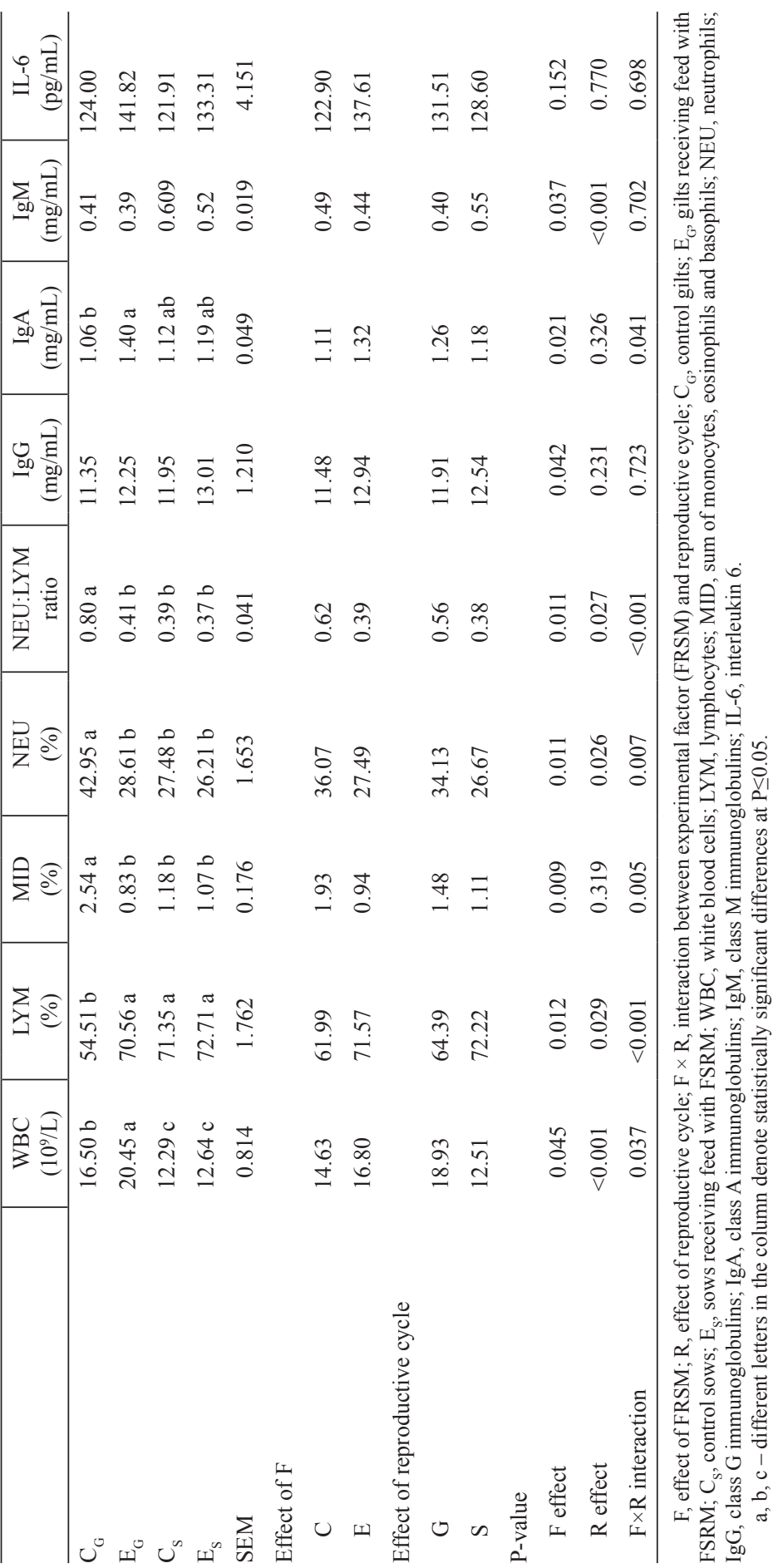




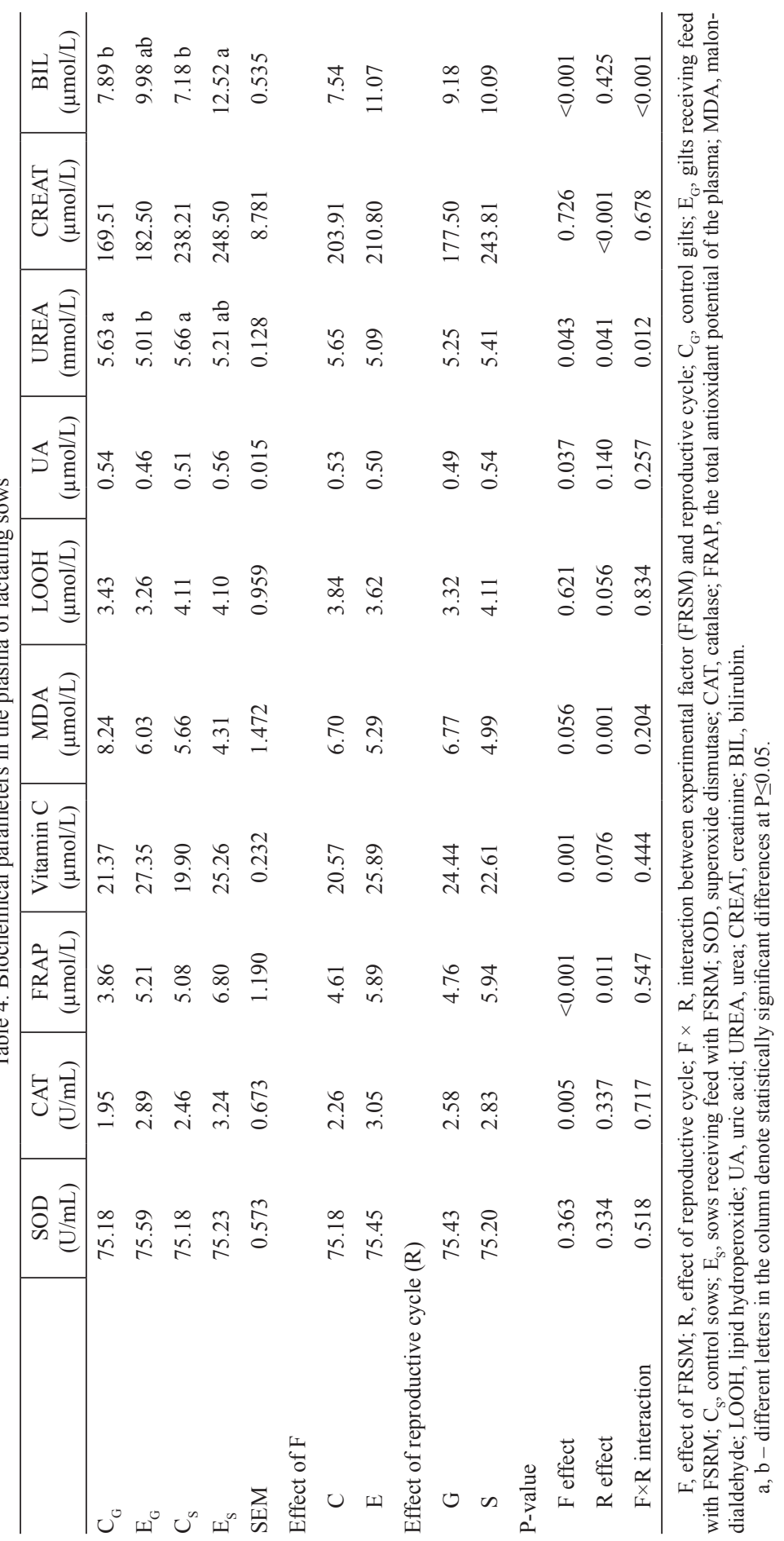




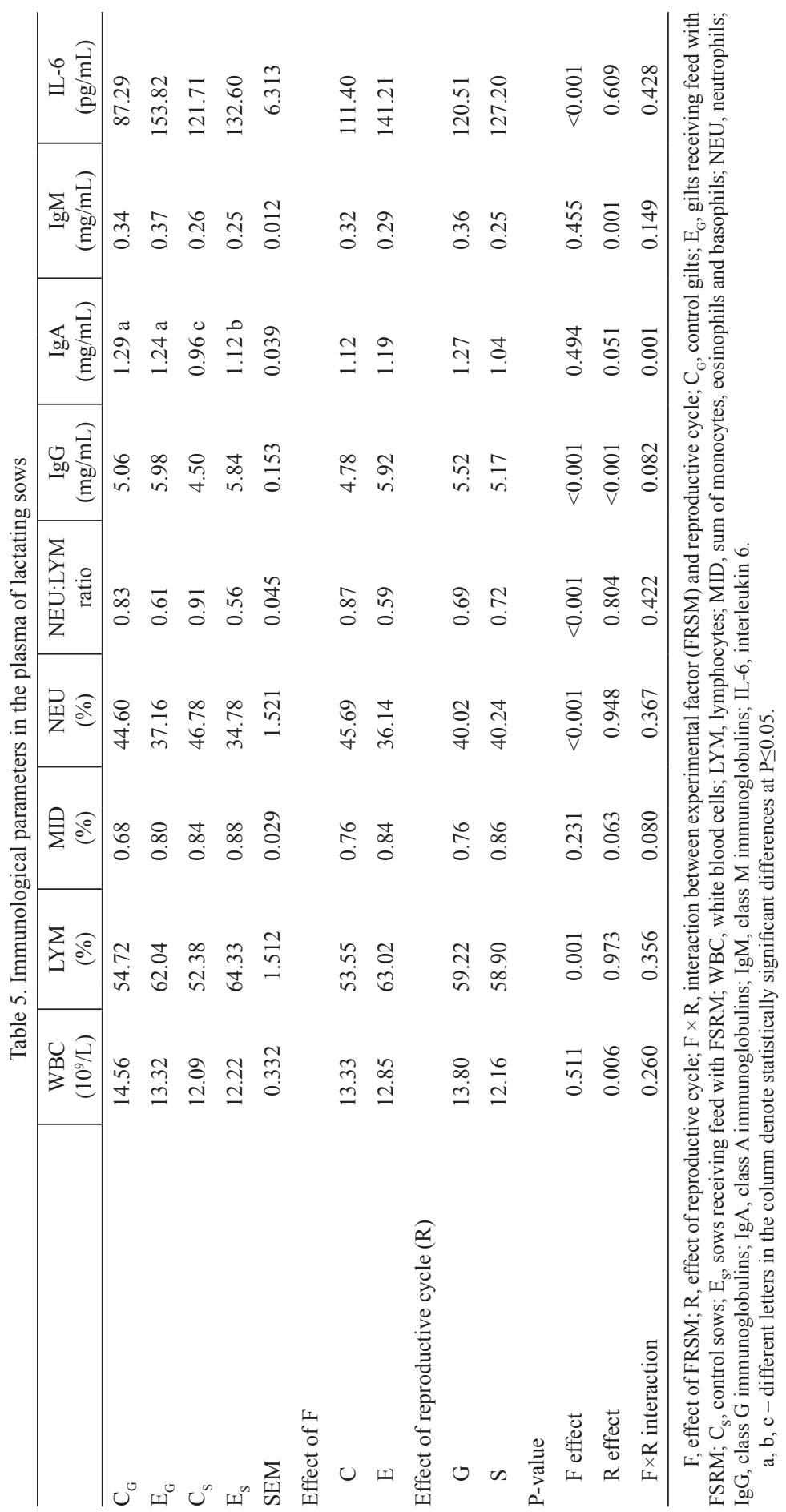




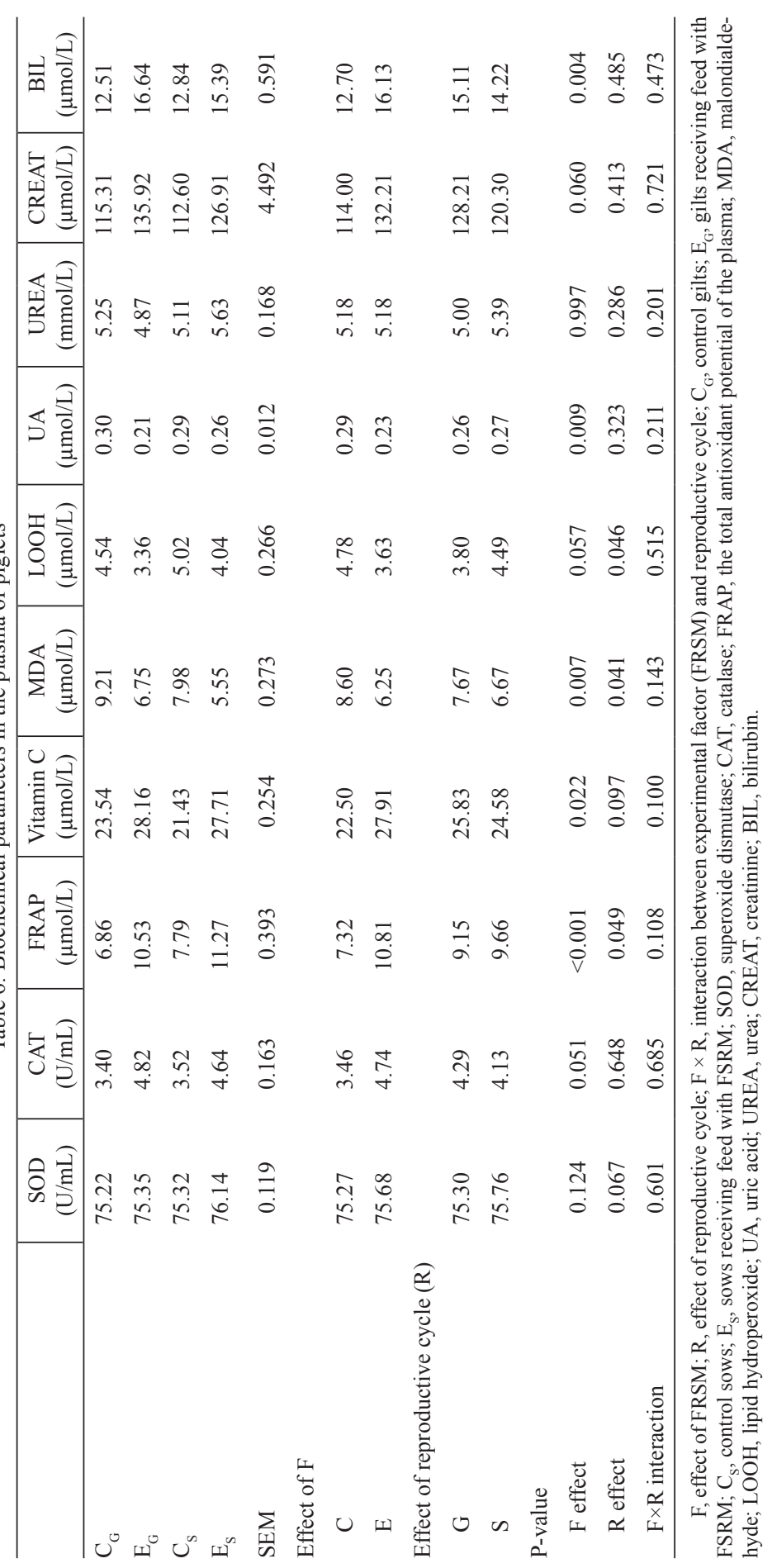




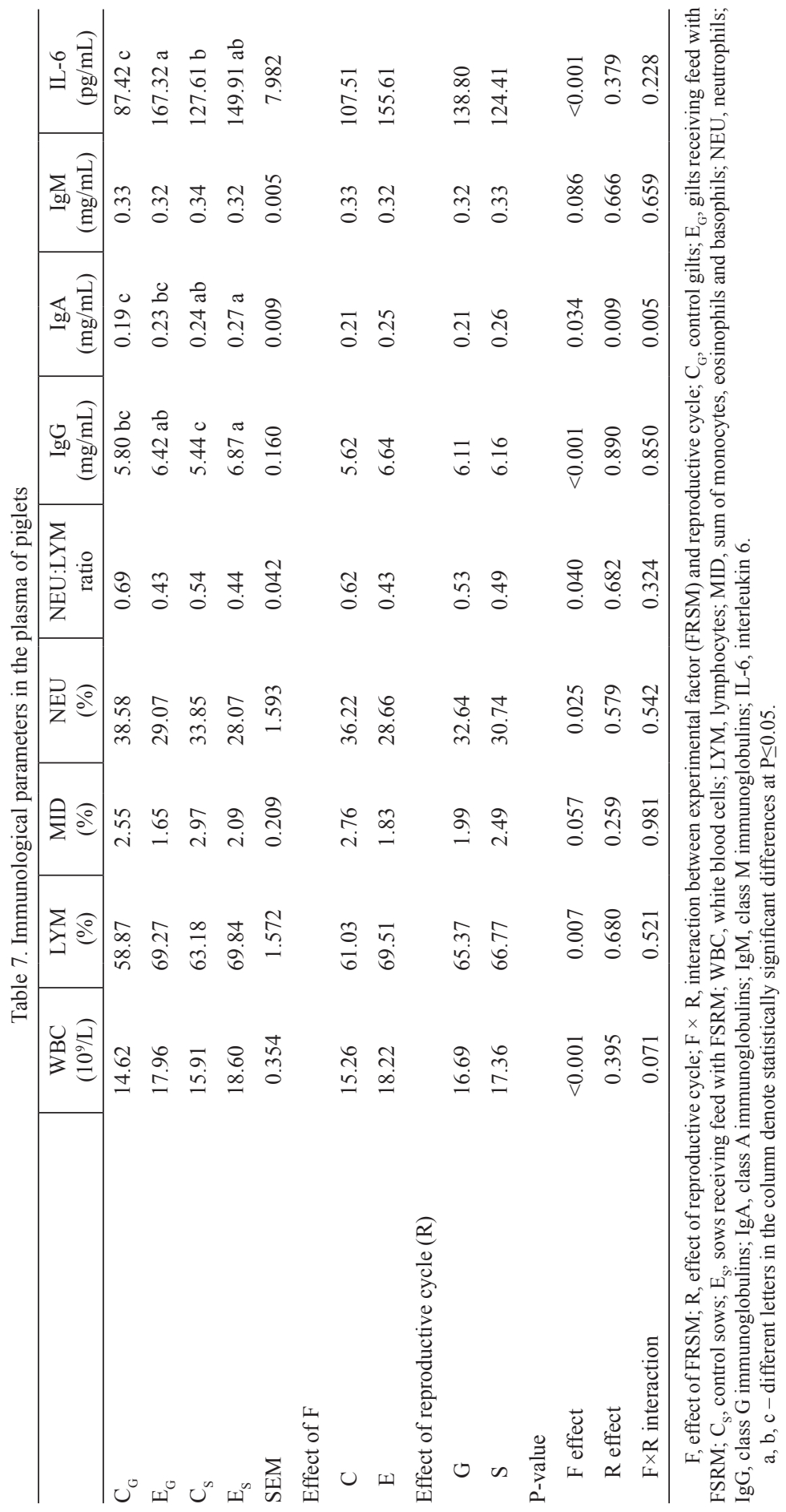




\section{Interaction FRSM $\times$ reproductive cycle}

Two-way ANOVA showed FRSM $\times$ reproductive cycle interactions for BIL level $(\mathrm{P}<0.001)$, IgA level $(\mathrm{P}=0.041)$, WBC $(\mathrm{P}=0.037)$, LYM $(\mathrm{P}<0.001)$, MID $(\mathrm{P}=0.005)$, NEU count $(\mathrm{P}=0.007)$ and NEU:LYM ratio $(\mathrm{P}<0.001)$ in blood plasma of pregnant sows. Multiparous pregnant sows receiving feed with FRSM $\left(\mathrm{E}_{\mathrm{S}}\right)$ had lower BIL level than multiparous pregnant sows from control group $\left(\mathrm{C}_{\mathrm{S}}\right)$. Such an effect was not observed in primiparous pregnant sows (Table 2). Primiparous pregnant sows receiving feed with FRSM $\left(\mathrm{E}_{\mathrm{G}}\right)$ had higher WBC, LYM count, and IgA level and lower MID, NEU count and NEU:LYM ratio than primiparous pregnant sows from control group $\left(\mathrm{C}_{\mathrm{G}}\right)$. Such an effect was not observed in multiparous pregnant sows (Table 3 ).

Two-way ANOVA showed also FRSM $\times$ reproductive cycle interactions for UREA ( $\mathrm{P}=0.012)$, BIL $(\mathrm{P}<0.001)$, and IgA content $(\mathrm{P}=0.001)$ in blood plasma of lactation sows. Primiparous lactation sows receiving feed with FRSM $\left(\mathrm{E}_{\mathrm{G}}\right)$ had lower UREA level than primiparous lactation sows from control group $\left(\mathrm{C}_{\mathrm{G}}\right)$. Such an effect was not observed in multiparous lactation sows (Table 4). Multiparous lactation sows receiving feed with FRSM $\left(\mathrm{E}_{\mathrm{S}}\right)$ had higher BIL and IgA level than multiparous lactation sows from control group $\left(\mathrm{C}_{\mathrm{S}}\right)$. Such an effect was not observed in primiparous lactation sows (Table 5).

Table 8. Correlation coefficients between the content of $\operatorname{IgG}, \operatorname{IgA}$ and $\operatorname{IgM}$ in blood plasma of pregnant sows, lactating sows and colostrum and their content in piglet's blood plasma

\begin{tabular}{lcccc}
\hline & $\mathrm{C}_{\mathrm{G}}$ & $\mathrm{E}_{\mathrm{G}}$ & $\mathrm{C}_{\mathrm{S}}$ & $\mathrm{E}_{\mathrm{S}}$ \\
\hline Pregnant sows vs piglets & & & \\
IgG & $-0.876^{*}$ & $0.643^{*}$ & $0.906^{*}$ & $0.849^{*}$ \\
Iga & -0.300 & $0.620^{*}$ & $-0.786^{*}$ & -0.457 \\
IgM & $0.844^{*}$ & -0.682 & -0.122 & 0.339 \\
Lactating sows vs piglets & & & & \\
IgG & 0.281 & $0.791^{*}$ & -0.119 & $0.797^{*}$ \\
Iga & 0.536 & -0.689 & -0.036 & -0.337 \\
IgM & 0.220 & 0.481 & -0.071 & -0.020 \\
Colostrum ${ }^{1}$ vs piglets & & & & \\
IgG & 0.202 & $0.800^{*}$ & 0.474 & 0.002 \\
IgA & -0.270 & $0.776^{*}$ & 0.154 & 0.081 \\
IgM & $-0.730^{*}$ & $0.703^{*}$ & -0.298 & 0.376
\end{tabular}

${ }^{*}$ Correlation is significant at $\mathrm{P}<0.05$.

${ }^{1}$ The results for calculating this correlation were taken from the publication by Grela et al. (2019) presenting results from the same experiment.

The assessment of the correlation coefficient between the content of $\operatorname{IgG}, \operatorname{IgA}$ and IgM immunoglobulins in the blood plasma of primiparous sows receiving FRSM $\left(\mathrm{E}_{\mathrm{G}}\right)$ and the amount of these immunoglobulins in the blood plasma of piglets from 
$\mathrm{E}_{\mathrm{G}}$ sows shows that there was a significantly positive correlation between IgG and IgA. A significant positive correlation regarding $\mathrm{IgG}$ was found in multiparous sows vs piglets in both the $\mathrm{C}_{\mathrm{S}}$ and $\mathrm{E}_{\mathrm{S}}$ groups. In the group of sows receiving fermented rapeseed meal $\left(\mathrm{E}_{\mathrm{G}}\right.$ and $\left.\mathrm{E}_{\mathrm{S}}\right)$, a significantly positive correlation was also found between the amount of IgG in the blood plasma of lactating sows and the amount of these immunoglobulins in the blood plasma of piglets. Moreover, a significant positive correlation was also found in the case of the content of all analyzed immunoglobulins between their content in the colostrum from the element receiving FRSM $\left(\mathrm{E}_{\mathrm{G}}\right)$ and the blood plasma of piglets from these sows (Table 8).

\section{Discussion}

The addition of FRSM component in diets significantly improves production parameters, mainly in primiparous gilts, leading to an increase in litter size and in litter weight at $28 \mathrm{~d}$ of age. It also helps to improve the digestibility of crude protein, fat and crude fiber (especially gilts during late pregnancy) and stimulates the immune system, which improves the health of piglets, reducing diarrhoea severity (Grela et al., 2019). The inclusion of fermented components in diets as a source of probiotic microorganisms (lactic acid bacteria), as well as short-chain fatty acids (including lactic acid), facilitates digestive tract function and improves nutrient availability (Wang et al., 2012). Research conducted by Grela et al. (2019) shows that the addition of a fermented rapeseed component to diets helped to improve the digestibility of crude protein (by up to $2.6 \%$ ), fat and crude fibre and positively affected the gut microbiota of sows (especially gilts during late pregnancy). This is especially important in sows during pregnancy and lactation, which are often accompanied by a limited capacity for food intake (Guillemet et al., 2006). This is due in part to stress resulting from the body's adaptation to changes in its physiological condition, accompanied by significant hormonal changes. Dynamic adaptive changes (anatomical, physiological and metabolic) taking place in sows during pregnancy, farrowing or weaning lead to oxidative stress, manifested by the generation of excessive reactive oxygen species (ROS). ROS not only can damage protein, lipid or DNA structures, but may cause gastrointestinal disorders as well (Yin et al., 2014).

Supported by exogenous antioxidants derived from fermented feed, the endogenous antioxidant system can compensate for excessive lipid peroxide production in the perinatal period and effectively protect against the effects of oxidative stress (Castillo et al., 2005). The increase in CAT activity in lactating sows fed a diet with FRSM and their piglets, as well as the increase in the FRAP in our experiment, reflects an improvement in their antioxidant status. The increase in FRAP induced by the addition of the fermented component coincided with higher plasma concentration of vitamin $\mathrm{C}$. It follows that the increased concentration of low-molecular-weight antioxidant was an important factor determining the total antioxidant potential of the plasma and thus the ability to scavenge free radicals. The effect of the fermented component on the content of other low-molecular-weight antioxidants that make up 
the FRAP value, such as UREA, CREAT or BIL, as well as on the activity of the antioxidant enzyme superoxide dismutase (SOD), was unclear (Ceriello et al., 1997). Stecchini et al. (2001) suggest that this may be due to the type of probiotic bacteria used, e.g. for the fermentation process. Most of them are involved in the synthesis of superoxide dismutase, which breaks down superoxide radicals to oxygen and hydrogen peroxide. Some species of lactic acid bacteria can synthesize catalase, which destroys hydrogen peroxide very rapidly and blocks the formation of peroxyl radicals (Knauf et al., 1992). Other species of lactobacilli produce non-enzymatic antioxidants, such as glutathione and thioredoxin, which are involved in the reduction of reactive oxygen intermediates (De Vos, 1996). Studies by Cai et al. (2014) and Wang et al. (2012) have found a greater ability to scavenge free radicals, including an increase in the activity of antioxidant enzymes, in the blood plasma of suckling and weaned piglets following the introduction of Lactobacilli sp. to the diet of sows.

Oxidative stress during pregnancy may result in impairment of the female immune system, which directly affects immunity in the offspring (Casanueva and Viteri, 2003). This effect was seen in our experiment in the control piglets (reduced lymphocyte count in favour of neutrophils and reduced plasma IgG titres). Weakening of the immune system may contribute to more frequent inflammation, leading to the activation of macro- and microphages, which produce large amounts of reactive oxygen species while fighting pathogens (Casanueva and Viteri, 2003). This can be slowed by supporting the immune system, e.g. with properly selected feed components. The addition of antioxidants or probiotics (Liu et al., 2018) or, as in our experiment, the inclusion of a fermented component in the diet, supports the production of lymphocytes and IgA and IgG immunoglobulins in pregnant sows. The stimulation of immune processes noted in both pregnant and lactating primiparous sows fed a diet with dried fermented rapeseed meal and in their piglets resulted in an increase in the number of lymphocytes produced in the bone marrow and entering the blood. The increase in lymphocyte counts in pregnant primiparous sows was accompanied by an increase in the level of class A secretory immunoglobulins. However, there were no changes in the level of IgM, whose role in the protection of mucous membranes is much smaller than that of IgA (Nagler-Anderson et al., 2001). These two immunoglobulins are closely linked and dependent on the continuous stimulation of mucosal immune cells by commensal intestinal bacteria, including lactic acid bacteria (Lactobacillus), such as those supplied with fermented feed (Nagler-Anderson et al., 2001). Studies by Campbell et al. (2013) indicate stimulation of the immune system to synthesize immunoglobulins, at both the local and systemic level, following the introduction of lactic acid bacteria into the body (e.g. with fermented feed). A high immunoglobulin titre in piglets may result from intensive utilization of maternal immunoglobulins, a higher immunoglobulin titre in the colostrum, or an immune response to an infection (Cai et al., 2014). This is highly beneficial, especially for newborn piglets, because their intestinal microbiota is not yet fully developed, and they lack their own specific immunity to protect them against environmental infections (Czech et al., 2010). Piglet resistance to infection is transmitted through the placenta and later the mother's milk, so an improvement in the sow's immune status improves immunity in her offspring (Czech et al., 2010; Grela et al., 2019). 
Our study indicated a significantly positive correlation between the content of immunoglobulins of both IgG, IgA and IgM classes in the colostrum of primiparous sows versus their content in the blood plasma of their piglets. In the colostrum of sows fed a diet including dried fermented rapeseed meal (Grela et al., 2019), a significant increase in the level of $\operatorname{IgG}$ by approx. $31 \%$ in multiparous and $40 \%$ in primiparous sows and IgM by about $2 \%$ in multiparous and $23 \%$ in primiparous sows was noted. This corresponded to a higher titre of these immunoglobulins in the blood plasma and was consistent with a study by Rooke and Bland (2002). Fermentation of rapeseed meal is an effective way to increase the level of lactic acid in diets, as well as to stimulate the immune system, which improves the health of piglets, reduce diarrhoea severity (by $72 \%$ in piglets born to multiparous sows and by $145 \%$ in piglets born to primiparous sows) and mortality (by $9.4 \%$ in piglets born to multiparous sows and by $141 \%$ in piglets born to primiparous sows) (Grela et al., 2019).

\section{Conclusion}

The inclusion of dried fermented rapeseed meal in the diet of sows stimulates antioxidant processes in primiparous and multiparous sows and in their piglets. This is responsible for stimulation of the immune system (increased LYM counts and IgG titres in the blood plasma). The inclusion of FRSM in the diet may be decisive in the maintenance of a specific balance between the humoral and cellular response, thus limiting the development of inflammation and atopy and enhancing immunoglobulin synthesis in the mother's body. Diet prepared with fermented rapeseed meal for pregnant sows, and especially lactating sows, also significantly improves acquired immunity by the offspring, as seen in the significant increase in IgG titres in the blood plasma. Our research on the use of dried fermented rapeseed meal in the diet of sows, particularly primiparous sows, is very promising. The use of greater amounts of this component in feed should be considered so as to limit the use of GMO plants.

\section{Conflict of interest}

We certify that there is no conflict of interest with any financial organization regarding the material discussed in the manuscript.

\section{References}

C a i C.J., C a i P.P., H o u C.L., Z e n g X.F., Q i a o S.Y. (2014). Administration of Lactobacillus fermentum I5007 to young piglets improved their health and growth. J. Anim. Feed Sci., 23: 222-227.

Campbell M., Crenshaw J.D., Polo J. (2013). The biological stress of early weaned piglets. J. Anim. Sci. Biotech., 4: 1-8.

Canibe N., Jensen B.B. (2012). Fermented liquid feed - microbial and nutritional aspects and impact on enteric diseases in pigs. Anim. Feed Sci. Technol., 173: 17-40.

C a s a n u e va E., Vi t e r i F.E. (2003). Iron and oxidative stress in pregnancy. J. Nutr., 133: 1700-1708.

Castillo C., Hernandez J., Bravo A., Lopez-Alonso M., Pereira V., Benedito J.L. (2005). Oxidative status during late pregnancy and early lactation in dairy cows. Vet. J., 169: 286-292.

Ceriello A., Bortolotti N., Falleti E., Taboga C., Tonutti L., Crescentini A., Motz E., Lizzio S., Rus so A., B artoli E. (1997). Total radical-trapping antioxidant parameter in NIDDM patients. Diab. Care, 20: 194-197. 
Czech A., Grela E.R. (2004). Biochemical and haematological blood parameters of sows during pregnancy and lactation fed the diet with different source and activity of phytase. Anim. Feed Sci. Technol., 116: 211-223.

C z e ch A., Gre la E.R., M o krzy ck a A., P e j s a k Z. (2010). Efficacy of mannanoligosaccharides additive to sows diets on colostrum, blood immunoglobulin content and production parameters of piglets. Pol. J. Vet. Sci., 13: 525-531.

Czech A., Ognik K., Laszewska M., S e mbrat ow ic z I. (2017). The effect of raw and extruded linseed on the chemical composition, lipid profile and redox status of meat of turkey hens. Anim. Sci. Pap. Rep., 35: 57-69.

Czech A., Grela E.R., K i esz M., Kły s S. (2020). Biochemical and haematological blood parameters of sows and piglets fed a diet with a dried fermented rapeseed meal. Ann. Anim. Sci., 20: 535-550.

D e Vo s W.M. (1996). Metabolic engineering of sugar catabolism in lactic acid bacteria. Antonie van Leeuwenhoek, 70: 223-242.

De cle r ck I., D ewulf J., P i e pers S., Decaluwé R., M a e s D. (2015). Sow and litter factors influencing colostrum yield and nutritional composition. J. Anim. Sci., 93: 1309-1317.

G a o J., Zhang H.J., Wu S.G., Yu S.H., Yo on I., M o o r e D. (2009). Effect of Saccharomyces cerevisiae fermentation product on immune functions of broilers challenged with Eimeria tenella. Poultry Sci., 88: 2141-2151.

Grela E.R., Czech A., Ki esz M., W lazło Ł., Nowakowicz-D ębek B. (2019). The effects of a fermented rapeseed meal additive on reproductive performance, nutrient digestibility, colostrum immunoglobulin content and microbial flora in sows. Anim. Nutr., 5: 373-379.

Guillemet R., Dourmad J.Y., Meunier-Salaun M.C. (2006). Feeding behaviour in primiparous lactating sows: Impact of a high-fiber diet during pregnancy. J. Anim. Sci., 84: 2474-2481.

J a k o bs en G.V., Jensen B.B., B a ch Knuds en K.E., B ro o k s N. (2015). Improving the nutritional value of rapeseed cake and wheat dried distillers grains with solubles by addition of enzymes during liquid fermentation. Anim. Feed Sci. Technol., 208: 198-213.

J h a R., L e terme P. (2012). Feed ingredients differing in fermentable fibre and indigestible protein content affect fermentation metabolites and faecal nitrogen excretion in growing pigs. Animal, 6 : 603-611.

Kirchges s ner M., R oth F.X. (1983). Schätzgleichungen zur Ermittlung des energetischen Futterwertes von Mischfuttermitteln für Schweine. Anim. Physiol. Anim. Nutr., 50: 270-275.

K n a u f H.J., Vog e 1 R.F., H a m m e s W.P. (1992). Cloning, sequencing, and phenotypic expression of katA, which encodes the catalase of Lactobacillus sake LTH677. Appl. Environ. Microbiol., 58: $832-839$.

L i u K., W u W., Li B., We i W., Li u Z., Li u H. (2018). Changes in oxidative stress status in sows from days 100 of gestation to post-partum estrus. Pakis. Vet. J., 38: 165-168.

M is s otten J.A.M., Michiels J., D e groote J., D e S met S. (2015). Fermented liquid feed for pigs: an ancient technique for the future. J. Anim. Sci. Biotechnol., 6: 4.

Nagler-Anders on C., Terhorst C., Bhan A.K., P od ols ky D.K. (2001). Mucosal antigen presentation and the control of tolerance and immunity. Trend Immun., 22: 120-122.

NRS (2012). Nutrient Requirements of Swine. 11th rev. ed. Washington, D.C. National Academies Press.

R o o k e J.A., B l a n d I.M. (2002). The acquisition of passive immunity in the new born piglet. Livest. Prod. Sci., 78: 13-23.

S t e c c h in i M.L., Torre M.D., M un ari M. (2001). Determination of peroxy radical scavenging of lactic acid bacteria. Int. J. Food Microbiol., 64: 183-188.

S u g i h a r to S., R a n j it k a r S. (2019). Recent advances in fermented feeds towards improved broiler chicken performance, gastrointestinal tract microecology and immune responses: A review. Anim. Nutr., 5: 1-10.

Tomaszewska E., Muszyński S., Dobrowolski P., Kamiński D., Czech A., Gre la E.R., Wi ą c e k D., To m c z y k - Wa r u n e k A. (2019). Dried fermented post-extraction rapeseed meal given to sows as an alternative protein source for soybean meal during pregnancy improves bone development of their offspring. Livest. Sci., 224: 60-68.

Wang J., Ji H.F., Wang S.X., Zhang D.Y., Liu H., Shan D.C., Wang Y.M. (2012). Lactobacillus plantarum ZLP001: In vitro assessment of antioxidant capacity and effect on growth 
performance and antioxidant status in weaning piglets. Asian-Australas J. Anim. Sci., 25: $1153-1158$.

Y in J., W u M.M., Xi a o H., R e n W.K., D u a n J.L., Yang G., L i T.J., Y in Y.L. (2014). Development of an antioxidant system after early weaning in piglets. J. Anim. Sci., 92: 612-619.

Received: 15 IX 2020

Accepted: 28 IV 2021 